\title{
ORIGINAL ARTICLE Resilience following spinal cord injury: a phenomenological view
}

\author{
KR Monden ${ }^{1}$, Z Trost ${ }^{2}$, D Catalano ${ }^{3}$, AN Garner ${ }^{2}$, J Symcox ${ }^{2}$, S Driver ${ }^{4}$, RG Hamilton ${ }^{5}$ and AM Warren ${ }^{6}$
}

Study design: Qualitative research design involving semi-structured focus groups.

Objectives: To increase current understanding of how persons with spinal cord injuries (SCl) define resilience and what factors contribute to their resilience or the resilience of others.

Setting: Inpatient rehabilitation program in a large urban city in the Southwestern United States.

Methods: A convenience sample of 28 participants (14 current patients; 14 former patients) participated in semi-structured focus groups led by the research investigators.

Results: Through a constant comparative analysis of the data, six themes emerged in participants' responses regarding what they believed contributed to their own resilience in adapting to $\mathrm{SCl}$. The six themes included psychological strength, social support, perspective, adaptive coping, spirituality or faith, and serving as a role model or inspiring others.

Conclusion: Consistent with previous research findings, individuals with $\mathrm{SCl}$ identified positive thinking (for example, optimism, hope and positive attitude), perseverance and determination, and social support from friends and family as important contributors to their ability to adapt in spite of experiencing traumatic events that resulted in SCl. Findings provide richness and depth to current empirical conceptualizations of resilience.

Spinal Cord (2014) 52, 197-201; doi:10.1038/sc.2013.159; published online 14 January 2014

Keywords: resilience; spinal cord injury; qualitative research; focus groups

\section{INTRODUCTION}

Traumatic spinal cord injuries (SCI) present serious public health and quality of life concerns. Costs associated with SCI are estimated at US\$9.7 billion annually, with average yearly expenses per individual ranging from $\$ 508904$ to $\$ 1044197$ in the first year following injury, and from $\$ 67415$ to $\$ 181328$ each subsequent year. ${ }^{1}$ SCI can result from an array of issues that affect physical, psychological and social functioning, which is reflected in the high cost of health-related services. Individuals who acquire an SCI experience numerous associated and chronic conditions (for example, spasticity, heart disease) and secondary complications (for example, pressure sores, chronic pain). Depression is a significant secondary complication for $\sim 30 \%$ of individuals with SCI, which often impacts physical health. ${ }^{2}$ In turn, depression has been associated with frequency of pressure sores, ${ }^{3}$ urinary tract infections, spending more time in bed and longer hospital stays. ${ }^{4}$

Given the interaction between psychological and physical health, an understanding of psychosocial functioning in the SCI population is essential. Despite an emphasis in the literature on less adaptive psychological outcomes following SCI, recent research shows that $\sim 60 \%$ of individuals who acquire SCI are not in fact depressed. ${ }^{2}$ Recent research also demonstrates that many individuals with SCI report moderate to very high resilience and a strong sense of self-efficacy. ${ }^{5}$

Recently, investigators have begun to explore the association between resilience and adaptation to traumatic injuries (and specifically to SCI). Resilience refers to effective coping and adaptation when faced with adversity and is defined as an individual's ability to flourish or bounce back in the face of adversity or a disruptive event. ${ }^{6}$ Research has begun to shed light on factors that contribute to resilience after SCI, including self-efficacy, ${ }^{5}$ proactive self-appraisals, cultivating positive emotions and strong social relationships. ${ }^{7-9}$ Resilience is likewise associated with various indicators of adjustment, including satisfaction with life, functional independence, spirituality and less depressive symptoms. ${ }^{10}$ Among individuals with SCI in acute rehabilitation and those living in the community, resilience is found to be negatively associated with depression $^{8}$ and positively associated with life satisfaction. ${ }^{7}$

Evidence likewise suggests that individuals who demonstrate high resilience at the start of rehabilitation will continue down a resilient path and achieve overall better recovery with fewer long-term psychosocial issues. ${ }^{6,10}$ Accordingly, resilience is increasingly identified as a relatively stable phenomenon that is associated with positive physical and psychological health outcomes. The demonstrated association between resilience and outcomes in the SCI population appears to represent a potentially important area for screening and intervention. As a result, further investigation of the resilience construct is warranted.

Although objective resilience measures are well validated in the literature, no study has yet addressed the qualitative nature of resilience among individuals with SCI. Such in-depth characterization

${ }^{1}$ Division of Surgical Education, Baylor University Medical Center, Dallas, TX, USA; ${ }^{2}$ Department of Psychology, University of North Texas, Denton, TX, USA; ${ }^{3}$ Department of Rehabilitation, Social Work, and Addictions, University of North Texas, Denton, TX, USA; ${ }^{4}$ School of Biological and Population Health, Oregon State University, Corvallis, OR, USA; ${ }^{5}$ Baylor Institute for Rehabilitation, Dallas, TX, USA and ${ }^{6}$ Division of Trauma, Baylor University Medical Center, Dallas, TX, USA

Correspondence: Dr KR Monden, Division of Surgical Education, Baylor University Medical Center, 3500 Gaston Avenue, Dallas, TX 75246, USA.

E-mail: kimberley.monden@baylorhealth.edu

Received 7 July 2013; revised 18 November 2013; accepted 1 December 2013; published online 14 January 2014 
of resilience may be essential towards developing a fuller understanding of the impact, mechanisms and potential avenues of intervention with respect to this construct. Therefore, the purpose of the current study was to conduct a series of focus groups comprising both inpatient and community-dwelling individuals with SCI to increase their current understanding of what factors they see as contributing to their own resilience and the resilience of others.

\section{MATERIALS AND METHODS}

The study protocol was approved by the hospital's institutional review board and informed consent was obtained from each participant. A convenience sample of individuals with SCI participated in a qualitative research design involving semi-structured focus groups facilitated by the research investigators. The current study sought to achieve a representative sample of both inpatient and community-dwelling individuals with SCI. In line with qualitative research recommendations, a sample size of $8-15$ participants is sufficient to reveal trends in the data and to gather information to the point of redundancy. ${ }^{11}$ Accordingly, the sample comprised 14 patients within an inpatient rehabilitation program in a large urban city in the Southwestern United States and 14 community-dwelling individuals who had previously completed rehabilitation either at the same hospital as the inpatients or an outside facility $(N=28)$. Sample demographics are displayed in Table 1 .

Inpatient participants were approached by a research assistant to inquire about study participation; outpatient participants included individuals who had indicated interest in continued research involvement following participation in prior studies as well as individuals who were currently attending outpatient support meetings at the facility. Outpatient participants were contacted in person (at support meetings), by email or by telephone. All patients invited to participate in the study agreed to do so. Inpatient participants ranged in age from 18 to 58 years, with an average of 0.21 years since injury. Outpatient participants ranged in age from 20 to 63 years, with an average of 7 years since injury.

To address what factors individuals believe contribute to their ability to overcome challenges and difficulties experienced after sustaining an SCI, a qualitative research approach using semi-structured, in-depth focus groups consisting of 2 to 4 participants was utilized. Each group comprised either current inpatients or individuals from the community. Focus groups were led by a research assistant and held in a private room of the inpatient rehabilitation hospital. A total of nine focus groups were conducted, digitally recorded and transcribed verbatim. The focus groups were structured by a set of predetermined questions derived from previous research ${ }^{12}$ and reviewed by an expert in the area of resilience and SCI. The groups were conducted with sufficient flexibility to enable participants to raise and discuss issues they considered important. The following main questions were used to encourage participants to expound on their experiences and perspectives with respect to the research question: (1) What helps you overcome or bounce back from difficult situations in your life? and (2) What motivates you to adjust or adapt to your injury? Follow-up questions or probes were utilized to encourage participants to explore concepts and themes that emerged from the conversation. ${ }^{11}$

Interview transcripts were coded and analyzed by the primary author and two research assistants throughout the course of the study so as to inform data collection for subsequent groups. ${ }^{11,13}$ Using aspects of grounded theory, participant responses were analyzed through a process of inductive reasoning and constant comparison analysis, which was used to identify underlying themes or codes within the data. Starting with a large set of descriptive codes or topic areas, the data were gradually reduced to a series of categories. These categories or themes were then examined to assess the extent to which there was consistency or divergence in participants' accounts and to identify factors believed by participants to promote resilience. Trustworthiness was established through investigator triangulation using three data-coders (that is, the principal investigator and two research assistants). Coding disagreements were discussed on an individual basis. To ensure fidelity of the qualitative analysis, an investigator with a background in resilience research also reviewed the coding completed by the core three-person research team. All applicable institutional and governmental regulations concerning ethical use of human volunteers were followed during the course of this research.
Table 1 Patient demographic and injury variables

\begin{tabular}{lll}
\hline Total sample $(\mathrm{N}=28)$ & Inpatients $(\mathrm{n}=14)$ & Community $(\mathrm{n}=14)$ \\
\hline Age & & \\
Mean 35 (s.d. 13) years & Mean 33 (s.d. 13) years & Mean 38 (s.d. 12) years \\
Median 33 years & Median 31 years & Median 40 years \\
Range 18-63 & Range 18-58 & Range 20-63
\end{tabular}

\section{Gender}

$\begin{array}{lll}\text { Female } 8(29 \%) & \text { Female } 4(29 \%) & \text { Female } 4(29 \%) \\ \text { Male } 20(71 \%) & \text { Male } 10(71 \%) & \text { Male } 10(71 \%)\end{array}$

Race

$\begin{array}{lll}\text { White } 21(75 \%) & \text { White } 12(85 \%) & \text { White } 9(64 \%) \\ \text { Black } 5(18 \%) & \text { Black } 2(14 \%) & \text { Black } 3(21 \%) \\ \text { Other } 2(7 \%) & \text { Other } 0(0 \%) & \text { Other } 2(14 \%)\end{array}$

\section{Education}

High school 5 (18\%) High school $4(29 \%) \quad$ High school $1(7 \%)$

Technical $1(4 \%) \quad$ Technical $1(7 \%)$

Technical $0(0 \%)$

Some college $5(18 \%) \quad$ Some college $3(21 \%)$

Some college $2(14 \%)$

Bachelor's 13 (46\%) Bachelor's $5(36 \%)$

Master's $1(4 \%)$

Master's $0(0 \%)$

Bachelor's 8 (57\%)

Professional 3 (11\%)

Professional $1(7 \%)$

Master's $1(7 \%)$

Professional 2 (14\%)

\section{Age at injury}

Mean 29 (s.d. 13) years Mean 32 (s.d. 13) years

Median 22

Median 31

Range 16-59

Range 17-57

Mean 25 (s.d. 13) years

Median 20

Range 16-59

Time since injury

Mean 7 (s.d. 10) years

Median 1

Mean 0.21 (s.d. 18) years Mean 13 (s.d. 11) years

Range 0.05-0.37

Median 0.14

Median 8

Range 0.05-0.75

Range 2-37

\section{Level of injury}

Cervical $13(46 \%)$

Thoracic $14(50 \%)$

Cervical 6 (43\%)

Cervical 7 (50\%)

Lumbar $1(4 \%)$

Thoracic $7(50 \%)$

Thoracic $7(50 \%)$

Lumbar $1(7 \%)$

Lumbar $0(0 \%)$

\section{Etiology of injury}

Traumatic $25(89 \%) \quad$ Traumatic $12(86 \%)$

Traumatic 13 (93\%)

Non-traumatic $3(11 \%) \quad$ Non-traumatic $2(14 \%)$

\section{RESULTS}

Qualitative analysis revealed a total of six metacodes or themes, which participants believed were important contributors to their ability to adapt in spite of experiencing traumatic events resulting in SCI. These metacodes included psychological strength, social support, adaptive coping, spirituality or faith, perspective, and being a role model or inspiring others. The six metacodes, their subcodes and frequencies are summarized in Table 2.

\section{Psychological strengths}

A prevailing theme described by participants across all nine focus groups was utilization of psychological strengths. Adaptive thinking styles and having expectations of a positive outcome have an important impact on people's response to adversity or challenge, and this was supported by participants' statements in the current study, such as: 
Table 2 Metacodes: frequencies and examples of quotations

\begin{tabular}{|c|c|c|}
\hline Metacodes and subcodes & Count & Example quotation \\
\hline $\begin{array}{l}\text { Psychological Strength } \\
\text { Positive attitude, adaptability, determination, } \\
\text { overcoming adversity, independence, } \\
\text { proactive behavior, assertiveness }\end{array}$ & 138 & $\begin{array}{l}\text { It's all about how you approach it. l've always been optimistic, but when I had my accident there were two ways } \\
\text { to go. There was either you can look at in an optimistic manner or you can just dwell on self-pity... my } \\
\text { personality just came out. I've never been a pessimistic person. I've always been optimistic. (positive attitude) } \\
\text { The will to fight for something and not just giving up. (determination) }\end{array}$ \\
\hline $\begin{array}{l}\text { Social support } \\
\text { Family, general, rehab staff, caregiver, } \\
\text { peer mentors }\end{array}$ & 85 & $\begin{array}{l}\text { It really does help to find a couple of people that you can really trust. Whether that be somebody that's in } \\
\text { rehab... there's just no way to do this by yourself. You cannot handle everything. It's just too hard more } \\
\text { emotionally than it is physically. Don't try to handle this by yourself. You will crash and burn. } \\
\text { (general social support) }\end{array}$ \\
\hline Perspective & 40 & $\begin{array}{l}\text { Just putting things into perspective. Sometimes when you're hit with something like that [SCI] it's really hard to } \\
\text { see the big picture. You are too focused on, you know, the damage control... somehow you have to find out this is } \\
\text { not the worst thing in the world that could happen to you. } \\
\text { Everything seems trivial after you've done this. } \\
\text { It's hard sometimes. You have a bowel accident. You're dealing with other things. It's hard to be positive. But my } \\
\text { thing is it's not always going to be like that... if you work through it. Life ain't a bowl of cherries, but if you're } \\
\text { willing to challenge yourself... life can be a beautiful thing. }\end{array}$ \\
\hline $\begin{array}{l}\text { Adaptive coping } \\
\text { Sense of humor, education, service dogs, } \\
\text { general coping strategies, goal-setting }\end{array}$ & 44 & $\begin{array}{l}\text { I find research really helpful. When I have a problem I'm facing I like to get on the Internet, read books, and try } \\
\text { to educate myself on it and try to figure all about it. (education) } \\
\text { Setting small goals. Making plans to be social, etc. It's something to look forward to. (goal-setting) }\end{array}$ \\
\hline $\begin{array}{l}\text { Spirituality/faith } \\
\text { Faith, fate, making meaning }\end{array}$ & 25 & $\begin{array}{l}\text { It wasn't God's plan for you to die. You're still here for a reason, but you've got to see that. You've got to be } \\
\text { willing to challenge yourself and really see what life has to offer you. (faith) } \\
\text { The fact that I'm still here motivates me. Because I feel like my task isn't over. (faith) }\end{array}$ \\
\hline Role model/inspiring others & 15 & $\begin{array}{l}\text { I've been doing this for } 20 \text { years. Mentoring, talking to people, going up to rehabs, trying to encourage them that } \\
\text { it's going to get better. If I can just get you to hold on. If I can get you to challenge yourself it's going to get } \\
\text { better. You're not always going to be in the hospital; not always going to be dependent on other people. It's } \\
\text { dependent on you. How far you want to take it. Get you to see what you are able to do instead of what you are not } \\
\text { able to do. I can change your life. And that's the difference. }\end{array}$ \\
\hline
\end{tabular}

For me, it's positive attitude, most importantly, and trying to do whatever I can not to dwell on the negative. And try to make a positive out of something, and as quick as possible try to find some sort of positive that is going to come out of this.-40-year-old male with tetraplegia

\section{Social support}

Social support emerged as a central theme for participants in the current sample. Receiving support from family, friends, caregivers, peer mentors and rehabilitation staff was described by participants as an integral factor in adapting to injury. Social support was discussed within the context of helping the individual adjust to his/her injury, and as a motivator for continuing with rehabilitation goals. For instance, one participant stated:

I have always had this feeling from the first year on, if I let this get me down and give up, not only am I letting myself down, but it would kill me more to let my family down because I saw what they sacrificed and how they care for me and how they make sure and don't treat me different. But they did little things like learning how to cath [catheterize]... if I gave up and said 'I'm done with it', it puts to shame everything they have done for me and I could never let my family down.-40-year-old male with tetraplegia

\section{Adaptive coping}

With respect to utilizing adaptive coping, participants identified specific strategies such as seeking education, having a sense of humor and general coping strategies (for example, music, journaling). For instance, a 29-year-old female with an incomplete cervical injury explained that she coped by:

Finding those things that you like. I mean like a temporary happiness. Finding something to read, watching TV and stuff. For me, it's like my friends write me notes and I read the notes. They make me laugh and for that moment you just kind of forget about it. And finding a new hobby, maybe that will help you bounce back a lot easier and just kind of give you a new motive or a new perspective on everything.

\section{Spirituality/faith}

Spirituality was a strong theme among participants in this study. Many participants felt that their spirituality, faith or ability to make meaning out of their experience had a significant impact on their ability to adapt. When expounding on the role of faith in his injury, one participant stated:

...I always believe that everything happens for a reason and everything [that has] happened in my life has prepared me for something else and it helped me prepare for this. I know that.40-year-old male with tetraplegia 


\section{Perspective}

Perspective was conceptualized as an individual's ability to find meaningful interrelationships with other events in their lives. This notion of seeing the 'big picture' was discussed primarily among participants who had transitioned back to the community. A 63-year-old female with tetraplegia described her ability to gain perspective regarding her injury as follows:

... I really wanted to live when I had the accident and I felt like I was at a crossroads. I could either die or I could live. So I came out of the accident being very positive. I have also lived long enough to know that nothing in life lasts forever and that your life goes through phases. It took me a while to realize that this is a new phase and I had to mourn the loss of my old phase... I might as well make the best of it because I look back on other times when life could have also come to an end.

\section{Being a role model or inspiring others}

Finally, many participants felt that being a role model or inspiring others was an important aspect in their ability to overcome or bounce back from injury. For instance, a 29-year-old female with tetraplegia described how inspiring others in turn motivated her:

I know a lot of people tell me, even though I'm just being me and trying to stay strong, that I motivate them or that I encourage them to keep going. And that kind of puts pressure on...it motivates you to keep going because you don't want to let other people down...even though it puts pressure on you not to let them down, it pushes you to keep going and makes you proud that you've kept going and motivates you at the same time.

\section{DISCUSSION}

In line with prior research, a prevailing theme described by participants across all nine focus groups was the utilization of psychological strengths. Previous studies indicate that a positive attitude is associated with resilience among populations with chronic illness. ${ }^{14}$ Similarly, individuals with SCI who report higher levels of hope also report higher functional skills and higher levels of participation in their recovery. ${ }^{15}$ Current study findings support the impact of adaptive thinking styles and positive outcome expectations on individuals' responses to adversity or challenge.

Likewise, social support emerged as a central theme for participants in the current sample. Social support and adaptive coping are routinely described as important factors in resilience, positive adjustment, life satisfaction and health-related outcomes among individuals with SCI. ${ }^{16,17}$ Both social support and problem-focused coping have been found to have a direct effect on resilience among individuals with SCI. ${ }^{8}$ Current study participants perceived receiving support from family, friends, caregivers, peer mentors and rehabilitation staff as an integral factor in adapting to injury.

Although several themes identified in our qualitative analysis are consistent with current literature on resilience (for example, psychological strengths, social support, spirituality), two novel themes emerged from the data, perspective and being a role model or inspiring others. Perspective appeared to be separate from spirituality or faith in that the participants' statements did not refer to a higher power or ability to find meaning in their injury from a religious or spiritual standpoint. In addition, while peer support has been shown to promote adjustment to $\mathrm{SCI},{ }^{18,19}$ to our knowledge the literature is limited in exploring outcomes associated with being a role model or inspiring others specifically in the SCI community. Further research is warranted to explore these constructs and their relation to an individual's ability to overcome adversity and adapt to SCI.

\section{Limitations}

Owing to the exploratory nature of this qualitative study tailored specifically to SCI, it is difficult to extrapolate the findings to non-SCI populations or draw definitive conclusions regarding the experience of resilience among persons with SCI. In addition, because no standardized mood assessment was conducted, we were unable to evaluate the possible impact of affective variables on participants' responses. Finally, some but not all participants were familiar with the primary group facilitator from previous hospitalizations or involvement in community support meetings. Such familiarity may have affected the comfort level among some participants, possibly influencing their responses.

Despite these limitations, the views expressed by the participants in this study are encouraging and informative for future empirical research and clinical intervention.

\section{CONCLUSIONS}

Although resilience has emerged as an important area of inquiry, there is a paucity of research that has examined the phenomenological experience of resilience from the perspective of persons with SCI. Accordingly, the present study contributes a level of richness and depth to current conceptualizations of resilience. Results reveal that individuals with SCI subjectively identify many of the same contributors to the ability to adapt that are demonstrated in recent empirical research on SCI and other traumatic conditions. Two novel themes also emerged from the data, gaining perspective and being a role model or inspiring others.

\section{DATA ARCHIVING}

There were no data to deposit.

\section{CONFLICT OF INTEREST}

The authors declare no conflict of interest.

\section{ACKNOWLEDGEMENTS}

We would like to thank Bliss Eckert who conducted and transcribed the focus group recordings. We would also like to thank Megan Self Reynolds who assisted our research support staff throughout this study.

1 National Spinal Cord Injury Statistical Center. Facts and Figures at a Glance. University of Alabama at Birmingham: Birmingham, AL, USA 2013, https://www.nscisc.uab.edu/.

2 Hoffman JM, Bombardier CH, Graves DE, Kalpakjian CZ, Krause JS. A longitudinal study of depression from 1 to 5 years after spinal cord injury. Arch Phys Med Rehab 2011; 92: 411-418.

3 Savic G, Short DJ, Weitzenkamp D, Charlifue S, Gardner BP. Hospital readmissions in people with chronic spinal cord injury. Spinal Cord 2000; 38: 371-377.

4 Richards JS, Kewman DG, Richardson E, Kennedy P. Handbook of rehabilitation psychology. Amer Psychol Assoc 2010; 1: 11-28.

5 Kilic SA, Dorstyn DS, Guiver NG. Examining factors that contribute to the process of resilience following spinal cord injury. Spinal Cord 2013; 51: 553-557.

6 Bonanno GA, Kennedy P, Galatzer-Levy IR, Lude P, Elfstrom ML. Trajectories of resilience, depression, and anxiety following spinal cord injury. Rehabil Psychol 2012; 57: 236-247.

7 Quale AJ, Schanke AK. Resilience in the face of coping with a severe physical injury: a study of trajectories of adjustment in a rehabilitation setting. Rehabil Psychol 2010; 55: 12-22.

8 Catalano D, Wilson L, Chan F, Chiu C, Muller VR. The buffering effect. of resilience on depression among individuals with spinal cord injury: a structural equation model. Rehabil Psychol 2011; 56: 200-211. 
9 Tugade MM, Fredrickson BL. Regulation of positive emotions: emotion regulation strategies that promote resilience. J Happiness Stud 2007; 8: 311-333.

10 White G, Driver S, Warren AM. Resilience and indicators of adjustment during rehabilitation from a spinal cord injury. Rehabil Psychol 2010; 55: 23-32.

11 Fassinger RE. Paradigms, praxis, problems, and promise: grounded theory in counseling psychology research. J Couns Psychol 2005; 52: 156-166.

12 Self M, Driver S, Stevens L, Warren AM. Physical activity experiences of individuals living with a traumatic brain injury: a qualitative research exploration. Adapt Phys Act $Q$ 2013; 30: 20-39.

13 Rubin HJ, Rubin IS. Qualitative Interviewing. The Art of Hearing Data. Sage Publishing: Thousand Oaks, CA, USA, 2005

14 Yorgason JB, Roper SO, Wheeler B, Crane K, Byron R, Carpenter L et al. Older couples' management of multiple-chronic illnesses: individual and shared perceptions and coping in type 2 diabetes and osteoarthritis. Fam Syst Health 2010; 28: 30-47.
15 Kortte KB, Stevenson JE, Hosey MM, Castillo R, Wegener ST. Hope predicts positive functional role outcomes in acute rehabilitation populations. Rehabil Psychol 2012; 57: 248-255.

16 Chronister JA, Chou CC, Frain M, Cardoso E. The relationship between social support and rehabilitation related outcomes: a meta-analysis. J Rehabil Psychol 2008; 74: 16-32.

17 Pentz M. Resilience among older adults with cancer and the importance of social support and spirituality-faith. J Gerontol Soc Work 2005; 44: 3-22.

18 Hass BM, Price L, Freeman JA. Qualitative evaluation of a community peer support service for people with spinal cord injury. Spinal Cord 2013; 51: 295-299.

19 Ljunberg I, Kroll T, Libin A, Gordon S. Using peer mentoring for people with spinal cord injury to enhance self-efficacy beliefs and prevent medical complications. J Clin Nurs 2011; 20: 351-358. 